\title{
Isolation and Identification of Organics-Degrading Bacteria From Gas-to-Liquid Process Water
}

\author{
Riham Surkatti ${ }^{1,2}$, Zulfa A. Al Disi ${ }^{3}$, Muftah H. El-Naas ${ }^{1 *}$, Nabil Zouari ${ }^{3}$, \\ Mark C. M. Van Loosdrecht ${ }^{2}$ and Udeogu Onwusogh ${ }^{4}$
}

${ }^{1}$ Gas Processing Center, Qatar University, Doha, Qatar, ${ }^{2}$ Department of Biotechnology, Delft University of Technology, Delft, Netherlands, ${ }^{3}$ Department of Biological \& Environmental Sciences, College of Arts Sciences, Qatar University, Doha, Qatar,

${ }^{4}$ Qatar Shell Research and Technology Center, Doha, Qatar

OPEN ACCESS

Edited by:

Kunal R. Jain,

Sardar Patel University, India

Reviewed by:

Jagat Rathod,

National Cheng Kung

University, Taiwan

Sikandar I. Mulla

REVA University, India

*Correspondence:

Muftah H. El-Naas

muftah@qu.edu.qa

Specialty section: This article was submitted to

Bioprocess Engineering,

a section of the journal Frontiers in Bioengineering and

Biotechnology

Received: 06 September 2020

Accepted: 30 November 2020

Published: 15 January 2021

Citation:

Surkatti R, Al Disi ZA, El-Naas MH,

Zouari N, Van Loosdrecht MCM and

Onwusogh U (2021) Isolation and

Identification of Organics-Degrading

Bacteria From Gas-to-Liquid Process

Water.

Front. Bioeng. Biotechnol. 8:603305.

doi: 10.3389/fbioe.2020.603305
The gas-to-liquid (GTL) process generates considerable amounts of wastewater that are highly acidic and characterized by its high chemical oxygen demand (COD) content, due to the presence of several organic pollutants, such as alcohols, ketones, aldehydes, and fatty acids. The presence of these organics in the process water may lead to adverse effect on the environment and aquatic life. Thus, it is necessary to reduce the COD content of GTL process water to an acceptable limit before discharging or reusing the treated water. Due to several advantages, biological treatment is often utilized as the main step in GTL process water treatment plants. In order to have a successful biotreatment process, it is required to choose effective and suitable bacterial strains that have the ability to degrade the organic pollutants in GTL process water. In this work, bacterial strains were isolated from the GTL process water, identified by 16S rRNA gene sequencing and then used in the biodegradation process. The detailed identification of the strains confirmed the presence of three organics-degrading bacteria identified as Alcaligenes faecalis, Stenotrophomonas sp., and Ochrobactrum sp. Furthermore, biodegradation experiments were carried out and confirmed that the pure culture as well as the mixed culture consortium of the bacterial strains has the ability to reduce the organic pollutants in GTL process water. However, the growth rate and biodegradation efficiency depend on the type of strains and the initial COD content. Indeed, the removal percentage and growth rate were enhanced after 7 days for all cultures and resulted in COD reduction up to $60 \%$. Moreover, the mixed culture of bacterial strains can tolerate and treat GTL process water with a variety of ranges of COD contents.

Keywords: GTL process water, isolation, identification, biodegradation, COD reduction

\section{INTRODUCTION}

Qatar is the capital of natural gas production and hosts the largest gas-to-liquid (GTL) plant in the world. During the GTL process, considerable amounts of water are often generated, due to the chemistry nature of the Fischer-Tropsch (F-T) process that is the main process in natural gas plants. The generated GTL process water contains several dissolved hydrocarbons that cannot be 
directly used or discharged to the aquatic environment. GTL process water is characterized by high acidity and high chemical oxygen demand (COD) content that can reach $32,000 \mathrm{mg} / \mathrm{L}$. The water is mainly contaminated with non-acid oxygenated (NAO) hydrocarbons, including ketones, aldehydes, alcohols, ethers, and esters (Zacharia et al., 2018). Thus, an appropriate treatment process should be applied to reduce the concentration of organics in GTL process water to the acceptable discharge limit. Since F-T water contains volatile organics and light oxygenates such as carbonyl compounds and $\mathrm{C}_{1}-\mathrm{C}_{3}$ alcohols which have boiling points less than that of water, they are typically treated using distillation or stripping columns. Therefore, the GTL wastewater treatment plant usually requires a pretreatment step such as stripping or distillation column to reduce the content of COD before the biological treatment process (Surkatti et al., 2020). The wastewater generated from the stripping/distillation column still contains large quantities of carboxylic acids and other oxygenates, which need to be treated biologically (Enyi et al., 2013).

The conventional activated sludge process, constructed wetlands, and trickling filters are nowadays among the most common biological technologies for the treatment of wastewaters, in addition to different types of membrane bioreactors (Shokrollahzadeh et al., 2008). For GTL process water, several biological treatments were combined with other treatment processes to achieve high COD reduction efficiency (Wang et al., 2016). However, the use of traditional anaerobic suspended sludge process has a major limitation in wastewater treatment. Therefore, new biological reactors were developed for the treatment of industrial wastewater, in which bacterial strains were used in the form of free or immobilized systems (El-Naas et al., 2013, 2016; Bouabidi et al., 2019).

In biological treatments, chemo-organotrophic species are considered as the main microbial degraders of organic pollutants in contaminated wastewaters (Fritsche and Hofrichter, 2008). A large range of organic compounds can be used by these chemoheterophic microorganisms, especially bacteria, as carbon and energy sources (Elbeshbishy, 2014). However, searching to extend the range of the organics that can be used, their admissible concentrations, and the efficiency of their removal is leading to continuous efforts deployed to isolate new strains or species having the ability to degrade all organics present in GTL process water. This is more needed for special situations of water generated in arid zones, like the Gulf area, characterized by harsh conditions (Disi et al., 2017). Indeed, the selection of any bacterial strain for a bioremediation process is based on its ability to tolerate harsh conditions, exhibiting a suitable activity for the existing organics in the treated water (Azubuike et al., 2016). Arid and semiarid areas are characterized by harsh weather with high temperatures that can affect bacterial populations and create a dynamic diversity of these bacteria, based on their ability to adapt by acquiring new metabolic activities and suitable surfactant production (Elazzazy et al., 2015). Local bacteria are then needed for the treatment of local GTL process water. Moreover, under harsh conditions, indigenous microorganisms have adapted to develop a specific metabolism, effective for these weathered organics (Kumar and Gopal, 2015). Indeed, many failures of bioremediation applications in areas characterized by harsh weather and soils can be attributed to the use of unacclimated bacteria and their associated activities (Disi et al., 2017).

The novelty of this work resides in the collection, isolation, and identification of indigenous bacteria from GTL process water available in Qatar. The same bacterial strains are then utilized for the biodegradation of major organic contaminants in local GTL process water. The main approach employed in this work is multidisciplinary, combining environmental microbiology, biochemistry, and bioremediation. This is important from fundamental and applied points of view for specific GTL process water generated and treated at harsh conditions.

\section{MATERIALS AND METHODS}

\section{Industrial Water Samples}

Process water samples were collected from a local GTL plant in Qatar, in which two types of water samples were analyzed and referred to as pretreated GTL process water and original GTL process water. The physical and chemical characteristics of the GTL process water samples are shown in Table 1. GTL process water is characterized by its high acidity and organic contents (high COD).

In order to investigate the organics present in GTL process water, a qualitative analysis using GC-MS was carried out for the GTL process water $(6,000 \mathrm{mg} / \mathrm{L}$ COD) and for pretreated GTL process water. In general, GTL process water contains alcohols, ketones, volatile fatty acids, ester, and other aliphatics. Based on the analysis, the main organic contaminants are short-chain alcohols and long-chain alcohols; it also contains some fatty acids, such as propenoic acid, butanoic acid, and acetoacetic acid, in addition to the esters, aliphatics, and ketones such as methyl ketone and pentanone. However, the type of organic pollutants is varied for the raw GTL process water and the pretreated GTL process water since the pretreated wastewater contains alcohols, ketones, and some aliphatics.

\section{Isolation and Purification of Bacterial Strains From Enrichment Cultures}

Luria-Bertani (LB) medium was used for the enrichment culture, isolation, and purification of the bacterial strains (Figure 1).

One milliliter of the GTL process water was suspended in $20 \mathrm{ml}$ liquid LB medium as the first enrichment step. The liquid cultures were incubated at $30^{\circ} \mathrm{C}$ in a rotating shaker set at 200 $\mathrm{rpm}$ for 3 days. At the end of the incubation period, $2 \mathrm{ml}$ from each liquid culture was transferred to $20 \mathrm{ml}$ mineral salts medium (MSM)-GTL as the adaptation step. The adaptation steps were repeated three times. Then, aliquots $(100 \mu \mathrm{l})$ of the MSM-GTL enrichment cultures were spread on solid LB agar medium. The $\mathrm{LB}$ plates were incubated at $30^{\circ} \mathrm{C}$ for $24 \mathrm{~h}$. Isolates exhibiting distinct colonial morphologies were isolated and transferred to separate LB agar plates for further purification. Consequent purification of the bacterial isolates was repeated six times using the streak plate method until pure isolates were obtained (Survery 
TABLE 1 | Physical and chemical characteristics of GTL.

\begin{tabular}{lcc}
\hline Characteristic & GTL process water & Pretreated GTL process water \\
\hline $\mathrm{COD}(\mathrm{mg} / \mathrm{L})$ & $5,000-7,000$ & $1,800-2,000$ \\
$\mathrm{TOC}(\mathrm{mg} / \mathrm{L})$ & $1,500-1,700$ & $700-800$ \\
$\mathrm{pH}$ & 2.9 & 2.9 \\
Conductivity & 0.435 & 0.430
\end{tabular}

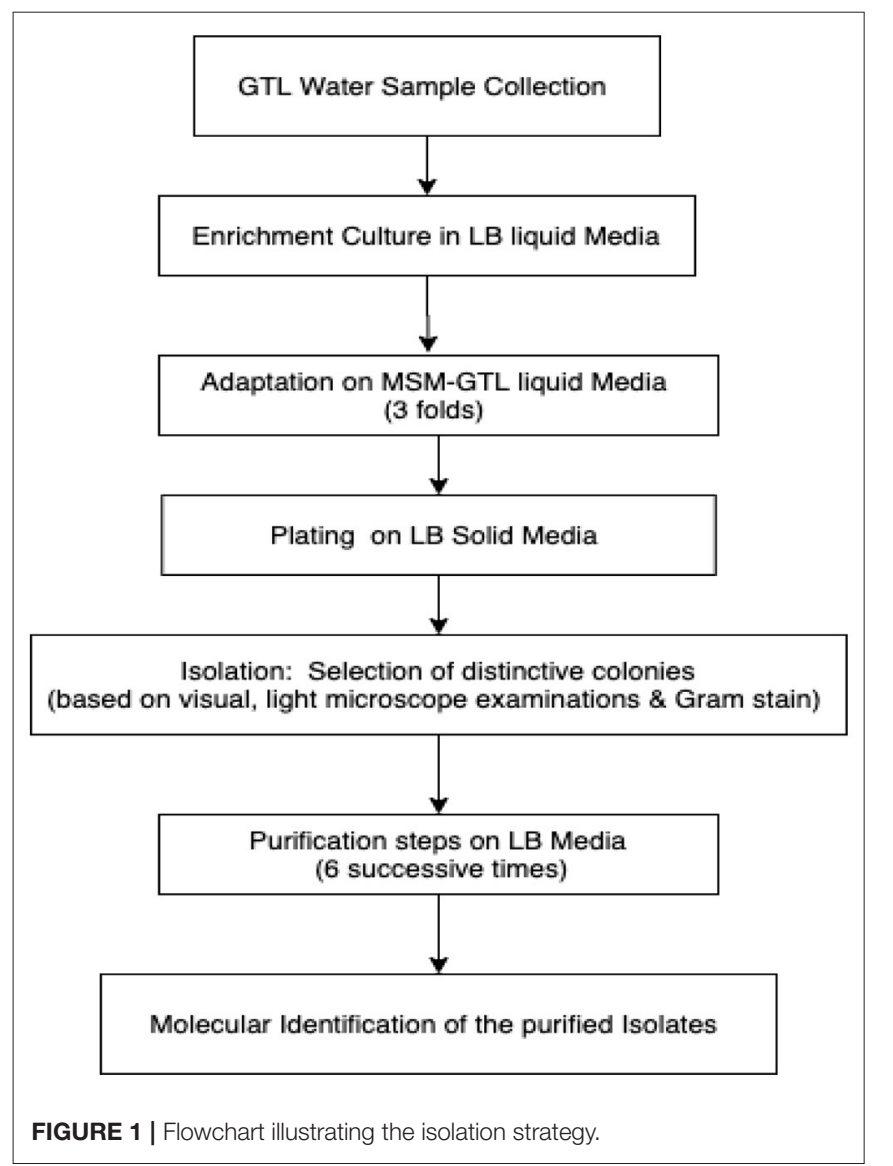

et al., 2005). Stock bacterial cultures were preserved at $-80^{\circ} \mathrm{C}$ in $30 \%$ glycerol until use.

\section{Evaluation of the Potential of Bacterial Strains to Remove COD in GTL Process Water}

Biodegradation experiments were performed using MSM liquid medium containing per liter ( $\mathrm{pH}$ 7.2): $\mathrm{NH}_{4} \mathrm{NO}_{3}, 4.0 \mathrm{~g} ; \mathrm{Na}_{2} \mathrm{HPO}_{4}$, $2.0 \mathrm{~g} ; \mathrm{KH}_{2} \mathrm{PO}_{4}, 0.53 \mathrm{~g} ; \mathrm{K}_{2} \mathrm{SO}_{4}, 0.17 \mathrm{~g} ; \mathrm{MgSO}_{4} \cdot 7 \mathrm{H}_{2} \mathrm{O}, 0.10 \mathrm{~g}$; and $1 \mathrm{ml} / \mathrm{L}$ of trace element solution (per $100 \mathrm{ml}$ ): EDTA, $0.1 \mathrm{~g} ; \mathrm{ZnSO}_{4}, 0.042 ; \mathrm{MnSO}_{4}, 0.178 \mathrm{~g} ; \mathrm{H}_{3} \mathrm{BO}_{3}, 0.05$; and $\mathrm{NiCl}_{2}$, $0.1 \mathrm{~g}$. The media were prepared using different concentrations of GTL process water. All media were sterilized by autoclaving at $121^{\circ} \mathrm{C}$ for $20 \mathrm{~min}$. Analysis was performed after the incubation periods to investigate the reduction in organic pollutants present in GTL wastewater. The bacterial growth was evaluated using the Lambda 25 UV/VIS spectrophotometer at $600 \mathrm{~nm}$. Samples were collected and analyzed at several time intervals to confirm the growth and the biodegradation efficiency of the isolated bacteria. All biodegradation experiments were carried out at optimal conditions, temperature of $30^{\circ} \mathrm{C}$ and $\mathrm{pH} 7$, since there was no growth or organic removal observed at room temperature $\left(\mathrm{T}=25^{\circ} \mathrm{C}\right)$ and $\mathrm{pH}$ values $(\mathrm{pH} 3.0$ and 5.0).

\section{COD Determination}

The COD analysis was carried out using a HAC-UV spectrophotometer with COD reagents. The analysis was obtained by adding $2 \mathrm{ml}$ of the water sample into the HAC LCK514 cuvettes and heating for $2 \mathrm{~h}$ to complete the reaction between the reagent and water sample. The sample was then transferred to the HAC 3900 to read the COD content in milligrams per liter. Each sample was analyzed in duplicate.

\section{Molecular Identification of Isolates}

The DNA was obtained from cells grown on LB solid media overnight at $30^{\circ} \mathrm{C}$. Pure colonies were suspended into Eppendorf tubes filled with $0.5 \mathrm{ml}$ of sterile distilled water. The Eppendorf tubes were incubated in a water bath set at $100^{\circ} \mathrm{C}$ for $10 \mathrm{~min}$ and then placed in an ice bath for $1 \mathrm{~min}$. After centrifugation for $60 \mathrm{~s}$ at $12,300 \mathrm{rpm}$, the supernatant containing total DNA was carefully transferred to a new sterile Eppendorf tube. The amplification of the 16S rRNA gene fragments of $\sim 1.5 \mathrm{~kb}$ was carreid out using two universal primers: RibS73sp 5' -AGAGTTTGATCCTGGCTCA-3' and RibS74sp 5'AAGGAGGTGATCCAGCCGCA-3' (Lane, 1991). The PCR reactions were performed in a total volume of $25 \mu$ l including $\mathrm{MgCl}_{2} 1.5 \mu \mathrm{M}$, dNTP $0.8 \mu \mathrm{M}$, forward primer $1.35 \mu \mathrm{M}$, reverse primer $1.35 \mu \mathrm{M}$, and $0.5 \mathrm{IU}$ Taq DNA polymerase; $2 \mu \mathrm{l}$ of genomic DNA from the isolates served as template for the PCR reactions.

The thermocycler program for each PCR reaction was intiated with a 3 -min denaturation step set at $94^{\circ} \mathrm{C}$, followed by 35 cycles of denaturation steps at $94^{\circ} \mathrm{C}$ with $45 \mathrm{~s}$ each, annealing step at $50^{\circ} \mathrm{C}$ for $45 \mathrm{~s}$, elongation step at $72^{\circ} \mathrm{C}$ for $45 \mathrm{~s}$, and then one final 2-min extension step at $72^{\circ} \mathrm{C}$. Consequently, the purification of PCR products was acomplished using an Invitrogen PureLink PCR Purification Kit. The DNA sequencing was performed using a Genetic Analyzer-Applied Biosystems 3,500 Series. The obtained sequences of 16S rRNA gene fragments were then compared with the most closely related species available in the GenBank database using the NCBI Blast server. Additionally, the phylogenetic tree of bacterial isolates was constructed by MEGA $\mathrm{X}$ software using the method of maximum likelihood (ML) based on the $16 \mathrm{~S}$ rDNA gene sequences.

\section{RESULTS AND DISCUSSION}

\section{Isolation and Molecular Identification of Bacteria From Qatari GTL Process Water}

Only three isolates (RZ3, RZ4, and RZ5) were obtained after enrichment cultures and isolation in LB medium. In fact, they 


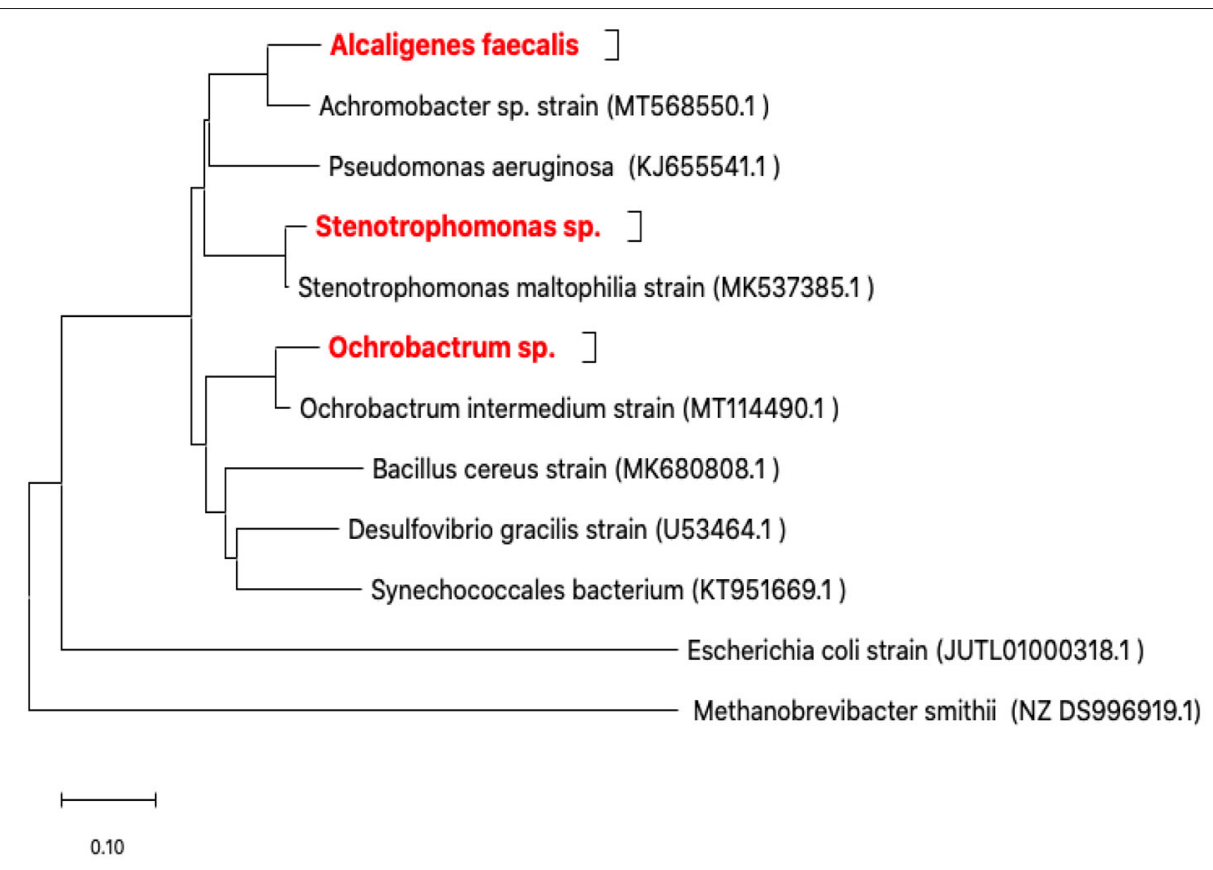

FIGURE 2 | Neighbor-joining phylogenetic tree based on 16S rRNA gene sequences showing the positions of the studied strains. Methanobrevibacter smithii from Archaea was the domain used for outgroup rooting. Achromobacter sp., Bacillus cereus, Desulfovibrio gracilis, Escherichia coli, Ochrobactrum intermedium, Pseudomonas aeruginosa, Stenotrophomonas maltophilia, and Synechococcales bacterium were used as reference bacterial strains. GenBank accession numbers are given in parentheses. The evolutionary history was inferred using the neighbor-joining method (Saitou and Nei, 1987). The optimal tree with the sum of branch length $=2.51758258$ is shown. The tree is drawn to scale, with branch lengths in the same units as those of the evolutionary distances used to infer the phylogenetic tree. The evolutionary distances were computed using the maximum composite likelihood method (Tamura et al., 2004) and are in the units of the number of base substitutions per site. This analysis involved 12 nucleotide sequences. All ambiguous positions were removed for each sequence pair (pairwise deletion option). There were a total of 1,790 positions in the final dataset. Evolutionary analyses were conducted in MEGA X (Kumar et al., 2018; Stecher et al., 2020).

TABLE 2 | List of previous works on the removal of organic compounds by the studied strains.

\begin{tabular}{|c|c|c|c|c|c|c|}
\hline Bacterial type & Bacterial source & Wastewater & Contaminant & $\begin{array}{c}\text { Initial } \\
\text { concentration } \\
(\mathrm{mg} / \mathrm{L})\end{array}$ & Removal \% & Reference \\
\hline Alcaligenes faecalis & $\begin{array}{l}\text { Durgapur steel industry } \\
\text { wastewater }\end{array}$ & Synthetic & Phenol & 1,600 & 100 & Jiang et al., 2007 \\
\hline Alcaligenes faecalis & Activated sludge & Synthetic & Phenol & 1,600 & 100 & Jia et al., 2005 \\
\hline Alcaligenes faecalis & $\begin{array}{l}\text { Activated sludge from } \\
\text { coke factory }\end{array}$ & Synthetic & Phenol & 1,000 & 100 & Essam et al., 2010 \\
\hline Stenotrophomonas sp. & Polluted river & Petroleum wastewater & Phenols & 998 & 89 & Patel and Patel, 2020 \\
\hline Stenotrophomonas sp. & Polluted river & Petroleum wastewater & COD & 15 & 93 & Patel and Patel, 2020 \\
\hline Stenotrophomonas sp. & Aquifer & Synthetic & $p$-Nitrophenol & 1.078 & 100 & Subashchandrabose et al., 2013 \\
\hline Ochrobactrum sp. & Textile sludge & Agricultural & COD & 11,707 & 71 & Neoh et al., 2016 \\
\hline Ochrobactrum sp. & Textile sludge & Agricultural & Ammonium nitrogen & 256 & 60 & Neoh et al., 2016 \\
\hline Ochrobactrum sp. & Textile sludge & Agricultural & $\begin{array}{l}\text { Total polyphenolic } \\
\text { compounds }\end{array}$ & 916 & 55 & Neoh et al., 2016 \\
\hline Ochrobactrum sp. & Marine environment & Petroleum & PAHs, COD & 1,000 & 66 & Arulazhagan and Vasudevan, 2011 \\
\hline Ochrobactrum sp. & $\begin{array}{l}\text { Phenol-activated } \\
\text { sludge }\end{array}$ & - & Phenol & 100 & 100 & El-Sayed et al., 2003 \\
\hline Ochrobactrum sp. & Polluted soil & - & p-Nitrophenol (PNP) & 100 & 100 & Qiu et al., 2007 \\
\hline
\end{tabular}

represent three types of colonies characterized by their form and color and the microscopic observation of the corresponding bacteria. The isolates were identified by ribotyping, based on sequencing of their 16S rDNA amplicons, after purification. The obtained 16S rDNA sequence of each isolate was used to determine the most closely related sequence of available 
sequences in the GenBank database using the Blast server at NCBI. The three isolates identified were as follows: Alcaligenes faecalis (RZ3), Stenotrophomonas sp. (RZ4), and Ochrobactrum sp. (RZ5) (Figure 2).

It can be concluded that a few strains were isolated. There are two possible reasons for this. The water samples contained highly toxic organic compounds, so that only the three isolated strains were able to tolerate this high level of water toxicity. The enrichment medium contained low nutrient contents, which may not be enough to sustain the required nutrients for cell growth and maintenance. Therefore, a few cells would have been able to adapt and subsist. This result shows that the isolation strategy was efficient to bacteria by enriching cultures in LB containing GTL process water. This culture medium was very toxic to bacteria because of the high organic concentration (COD ranging from 6,000 to $7,000 \mathrm{mg} / \mathrm{L}$ ). The aim of the isolation procedure was to isolate and purify bacteria with strong potentials to degrade and tolerate GTL process water.

The isolated bacteria have been widely applied in the treatment of different GTL process water containing a variety of organic contaminants. Table 2 summarizes the application of these strains in wastewater treatment in previous studies. A. faecalis shows high performance in the removal of ammonia from wastewaters (Neerackal et al., 2016). However, it has high tolerance in phenol removal from wastewater, even at very high initial concentrations (Bai et al., 2007). It was confirmed by Essam et al. (2010) that an isolated strain of $A$. faecalis has the ability to grow in phenol; however, it has difficulty to grow and remove other phenol derivatives, such as nitrophenols and chlorophenols. Additionally, the bacterium was shown with low tolerance to grow in alcoholic compounds such as methanol and ethanol (Essam et al., 2010). Stenotrophomonas sp. is reported with its tolerance in heavy metal removal (Gunasundari and Muthukumar, 2013); however, it showed good performance in the removal of phenols and organic carbon present in refinery wastewaters (Patel and Patel, 2020). Ochrobactrum sp. is a Gramnegative, rod-shaped, aerobic and oxidase-positive bacterium (Arulazhagan and Vasudevan, 2011). This bacterium showed high treatment performance of several contaminants present in wastewaters (Qiu et al., 2007). Neoh et al. (2016) showed that Ochrobactrum sp. has high performance in the biotreatment of agricultural wastewaters that contain high COD and nitrogen contents. In addition, Ochrobactrum sp. has high performance in the removal of phenol and its derivatives (El-Sayed et al., 2003; Qiu et al., 2007). The removal of the organic compounds present in the GTL process water was not documented using the isolated strains.

\section{Biodegradation of Organic Pollutants From GTL Process Water Organic Removal Using Several Strains}

The potential of the isolated bacterial strains in the removal of organic compounds present in the Qatari GTL process water using pure and mixed cultures was evaluated. The GTL process water used in this section was obtained after the pretreatment process and has COD content of $1,800 \mathrm{mg} / \mathrm{L}$. A set of 14 experiments were performed using the MSM-GTL medium to screen the isolated strains for the biodegradation of organic pollutants in GTL wastewater. All samples were kept in the incubator in which the COD content and biomass growth (biomass production) were evaluated at 3, 7, 10, and 14 days. The growth curves of single and mixed cultures are shown in Figure 2. It is clear that the three strains reach their maximum growth after 3 to 4 incubation days. Interestingly, the growth started immediately after inoculation, without a clear lag phase. This means that all the strains are highly adapted to the substrates, which are the organic compounds in GTL process water including alcohol, ketones, esters, and aliphatics. However, a clear decline in growth was observed after this period. The period of high growth was marked with a fast decrease of the COD content, which continued up to the 7th day (Figure 3). Nevertheless, there was no further COD reduction observed after

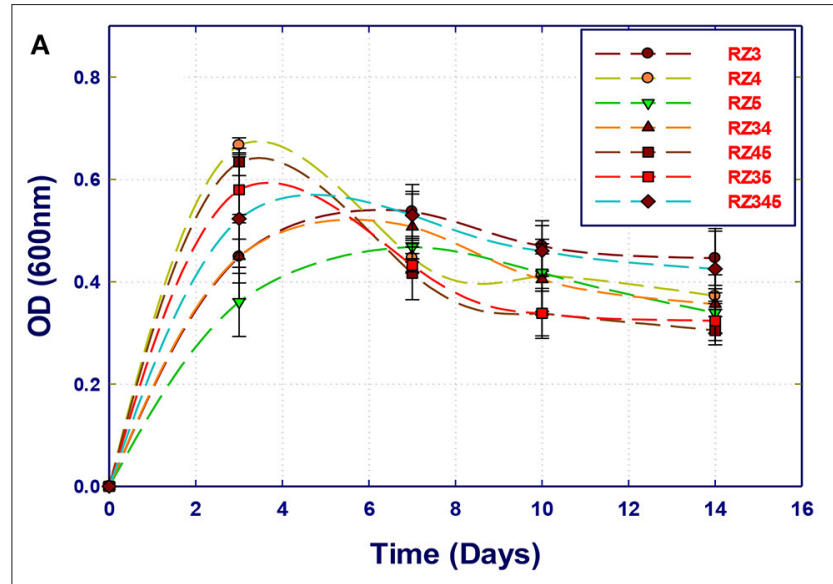

B

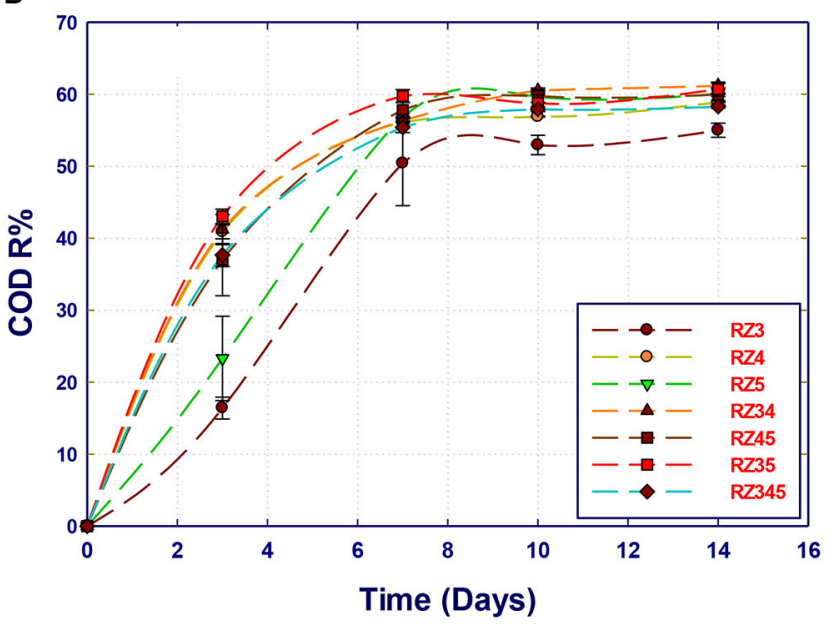

FIGURE 3 | Comparison of the biotreatment of GTL process water using several bacterial strains: single, co-culture, and mixed culture. (A) Biomass growth; (B) COD reduction. 
a 1-week incubation. When comparing the growth curves and corresponding COD reduction curves for each single or mixed culture, it can be noticed that the strain Stenotrophomonas sp. (RZ4) showed the highest growth rate as a single culture, followed by the mixture Stenotrophomonas sp. with Ochrobactrum sp. (RZ5). Although Ochrobactrum sp. growth was the least as a single culture, a clear symbiotic and cooperation can improve the growth of Ochrobactrum sp. by the concomitant growth of Stenotrophomonas sp. A pure culture of Ochrobactrum sp. can also achieve around 56\% COD reduction similar to that obtained by Stenotrophomonas sp. alone or by Stenotrophomonas sp. and Ochrobactrum sp. after 14 incubation days. However, the yield of Ochrobactrum sp. in biomass production was lower than that of Stenotrophomonas sp.

The strain A. faecalis (RZ3) also showed less growth rate than that of Stenotrophomonas sp. alone, which is reflected in
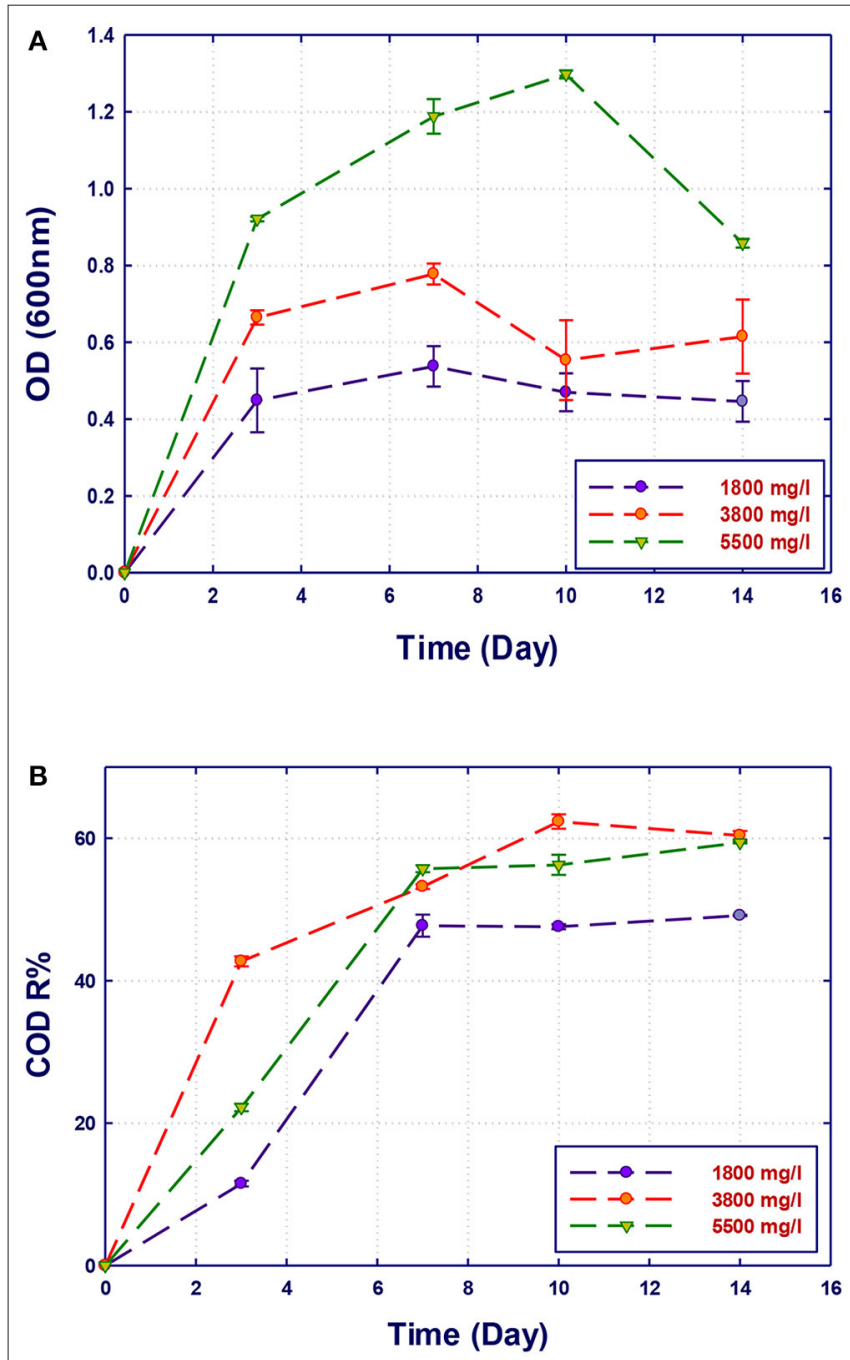

FIGURE 4 | Biological treatment of GTL process water using Alcaligenes faecalis (RZ3). (A) Biomass growth; (B) COD reduction. a slightly lower COD reduction (52\%). Mixing A. faecalis with Stenotrophomonas sp. did not improve its growth, although the COD reduction was improved to the best level. In contrast, the combination of the three strains resulted in biomass growth and COD reduction similar to that of Stenotrophomonas sp. alone. It seems that the strain Stenotrophomonas sp. can be used alone to remediate the Qatari GTL process water at these conditions (COD 1,800 mg/L).

\section{Effect of COD Concentration on Biodegradation Performance}

The performance of the isolated strains to grow and remove organics in GTL process water at three initial COD contents $(1,800,3,800$, and $5,500 \mathrm{mg} / \mathrm{L})$ was investigated. The initial COD content of the raw GTL process water was $5,500 \mathrm{mg} / \mathrm{L}$, which was pretreated to reduce its concentration to $1,800 \mathrm{mg} / \mathrm{L}$. The third COD content $(3,800 \mathrm{mg} / \mathrm{L})$ was obtained by diluting the initial raw GTL process water. The biodegradation performance of pure and mixed culture of the three strains was evaluated at
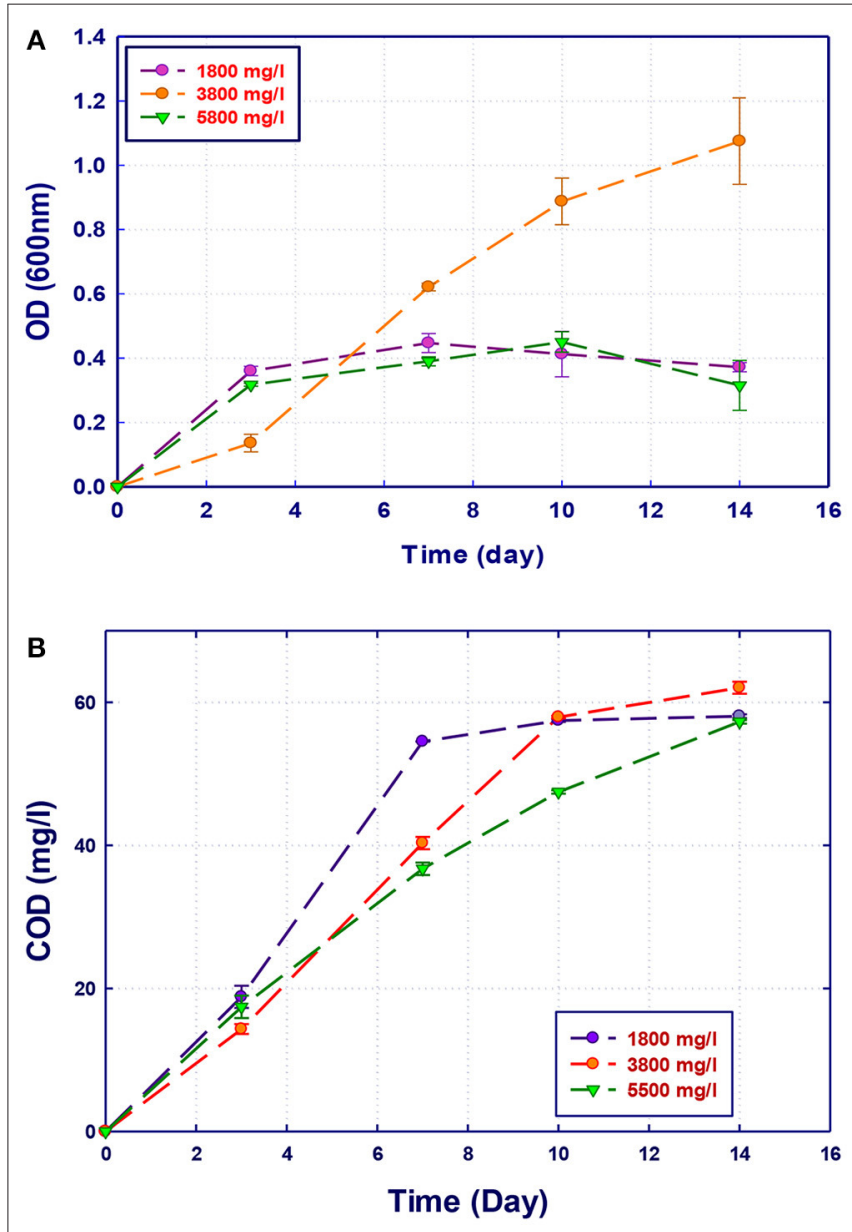

FIGURE 5 | Biological treatment of GTL process water using Stenotrophomonas sp. (RZ4). (A) Biomass growth; (B) COD reduction. 
each COD content. The biomass growth and COD reduction for each water sample (with different COD concentrations) are shown in Figures 4-7. Interestingly, the results of Figure 4 show that the strain A. faecalis (RZ3) is not inhibited by the excess of organic pollutants (high COD process water) since an increase of the growth rate is related to COD increase. Moreover, the overall removal of COD after 14 days of incubation was almost similar (60\%). This may be attributed to the ability of A. faecalis to remove several organic pollutants in GTL wastewater including fatty acids that are available in the raw GTL process water.

The growth of both strains Stenotrophomonas sp. (RZ4) and Ochrobactrum sp. (RZ5) was negatively affected by the increase of the COD content in the growth medium. This means that these strains may be inhibited by the excess of substrates or inhibited by several organics present in GTL process water. The combination of the three strains showed high ability in the degradation of organic pollutants present in GTL process water,
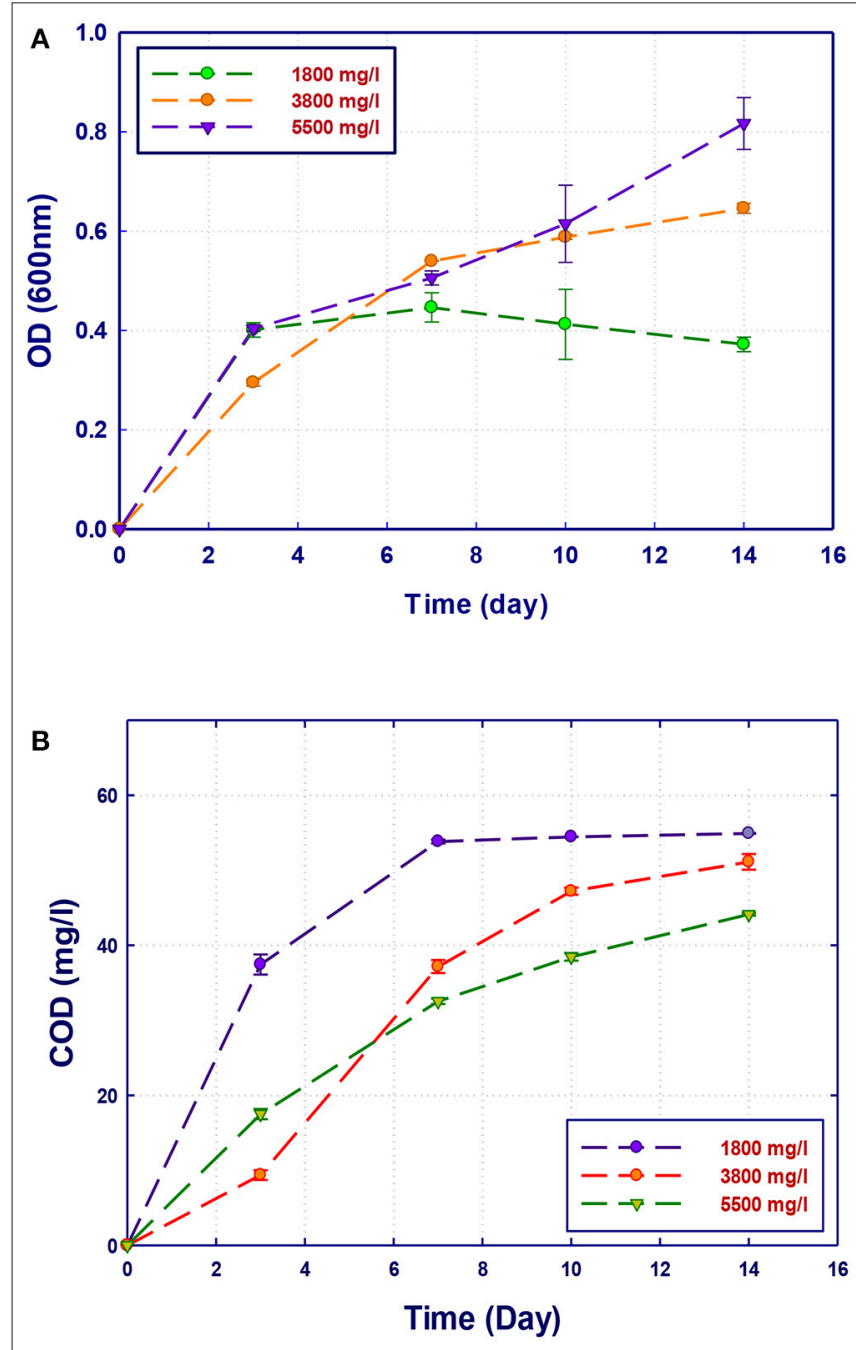

FIGURE 6 | Biological treatment of GTL process water using Ochrobactrum sp. (RZ5). (A) Biomass growth; (B) COD reduction. which indicates the synergy effect for several strains in the GTL wastewater treatment.

Although the three isolates were capable of degrading the organic pollutants in GTL process water at various COD contents, the removal of these organic contaminants by mixed cultures was improved compared with individual strains as shown in Figure 7. Each individual microorganism may have the ability to metabolize limited types of substrates; thus, the combination of different bacterial strains with wider enzymatic capabilities will result in the degradation of more organic pollutants giving higher COD reduction. This was confirmed by Senthilvelan et al. (2014) when they tested phenol degradation using single strains and mixed culture. In their study, a significant increase in the biodegradation rate and phenol removal was obtained using mixed microbial culture.

Since short-chain alcohols (SCA) represent about $82 \%$ of the COD content of GTL process water (Majone et al., 2010), GC analysis was carried out to determine their concentrations in
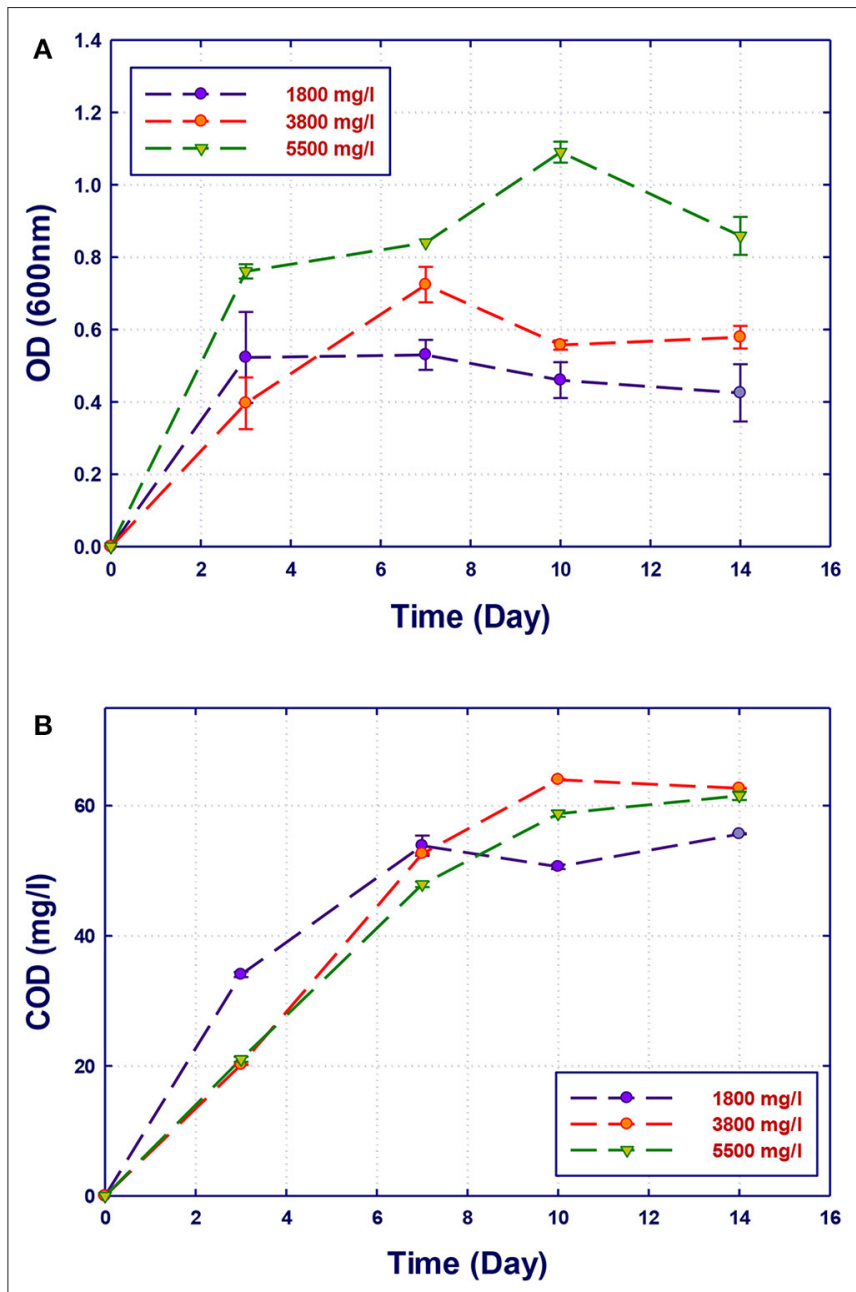

FIGURE 7 | Biological treatment using mixed culture of Alcaligenes faecalis, Stenotrophomonas sp., and Ochrobactrum sp. (RZ 345). (A) Biomass growth; (B) COD reduction. 
A

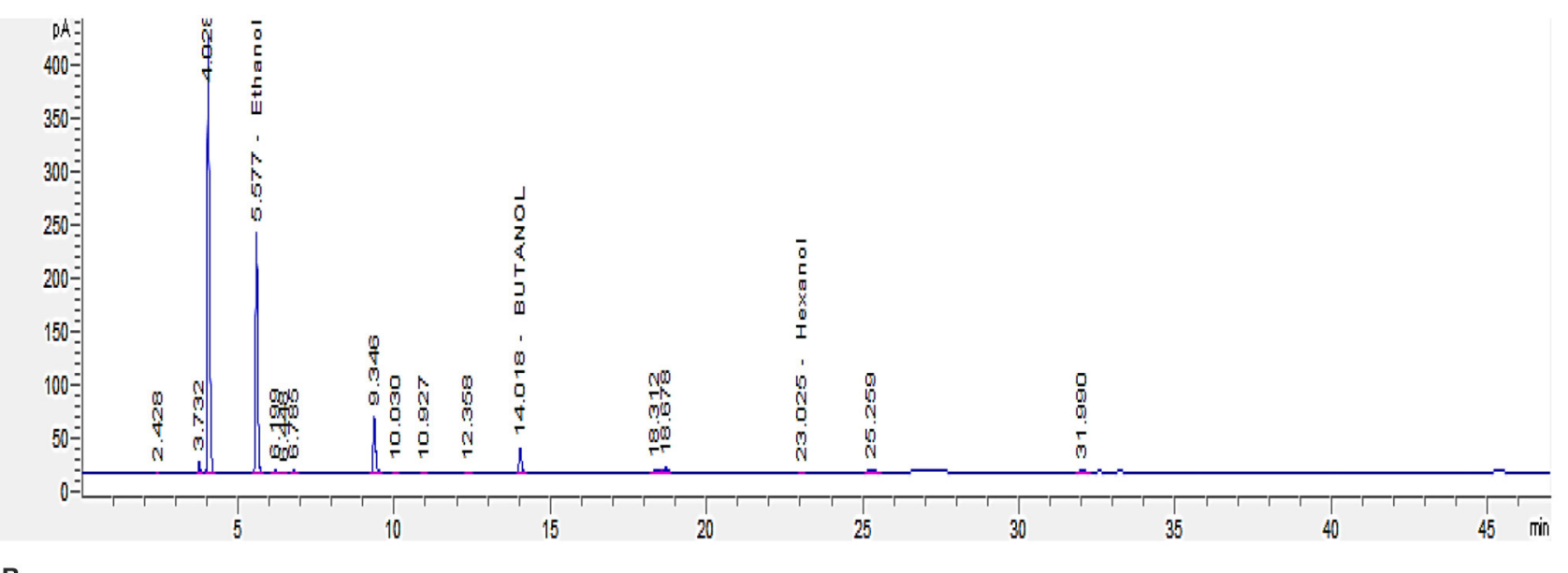

B

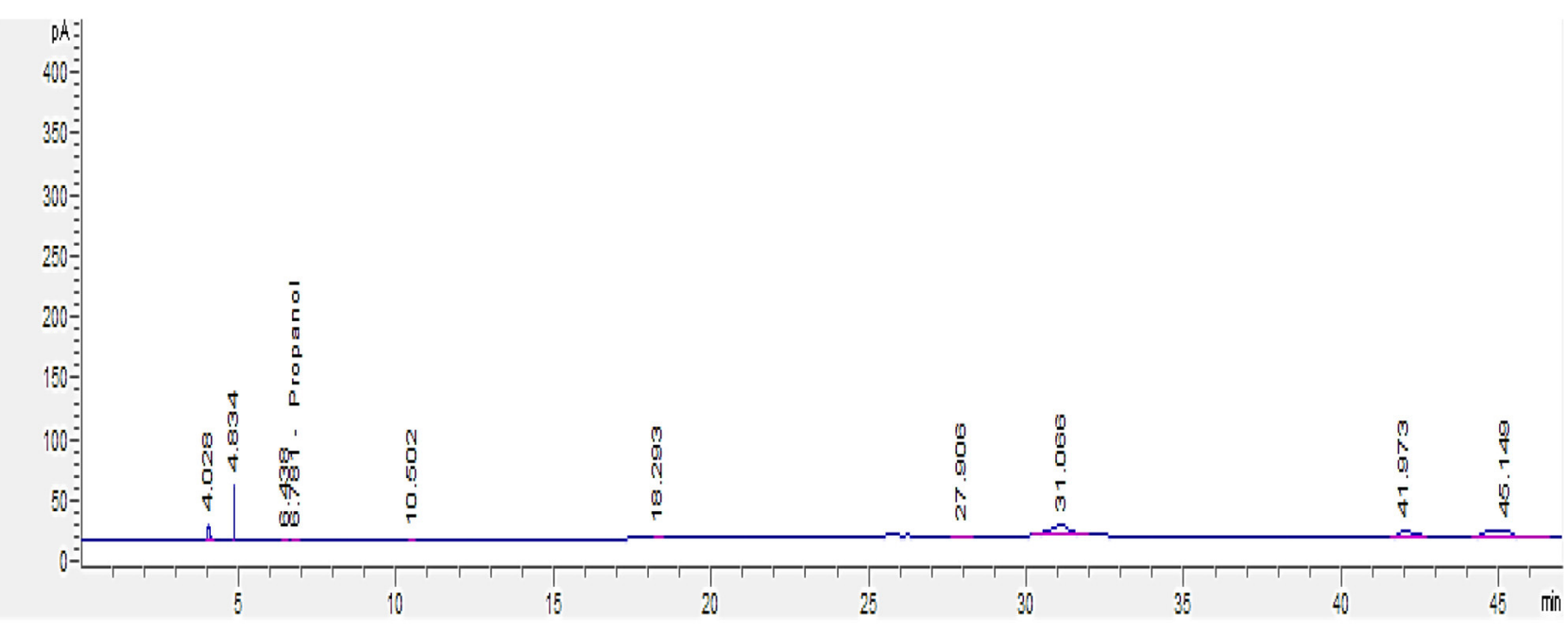

FIGURE 8 | GC analysis for short-chain alcohols (C1-C6) in GTL process water: (A) before and (B) after biotreatment.

GTL process water before and after biotreatment. GTL process water and biotreated water contain SCA (C1-C6) concentration of 2,465 and $813 \mathrm{mg} / \mathrm{L}$, respectively (Figures 8A,B). The analysis showed that the isolated bacteria were able to degrade around $60 \%$ of the short-chain alcohols.

Since the SCA are the major contributor to the COD content in GTL process water, it is important to reduce their concentration through biotreatment, in order for the treated water to be reused or discharged safely.

It is obvious that GTL process water has a broader range of organic pollutants. This may require the application of several types of microorganisms in order to achieve high degradation performance. Thus, it is recommended to use mixed bacterial strains for the biological treatment of GTL process water, at different ranges of COD contents. The main novelty of this study is the application of the isolated strains to remove the organic pollutants in the same GTL process water and achieve high COD reduction under stress conditions, which has not been reported before.

\section{CONCLUSIONS}

It is evident from this study that GTL process water is a rich source of organic components that are rather difficult to remove or degrade. However, the isolation, identification, and testing of organics-degrading bacterial strains, such as $A$. faecalis, Stenotrophomonas sp., and Ochrobactrum sp., from GTL water showed that these strains have the capability to degrade the organic contaminants in GTL water and can be a good alternative for the conventional activated sludge systems, which are currently applied in the biological treatment of GTL process water. Each bacterial strain has the ability to work as a single strain or in a mixed culture to remove the organic pollutants 
present in GTL process water. Regardless of the complex composition of GTL process water, the isolated strains resulted in high COD reduction (up to 60\%) under stressed conditions and, consequently, had high growth performance in such industrial wastewater.

\section{DATA AVAILABILITY STATEMENT}

The datasets generated for this study can be found in online repositories. The names of the repository/repositories and accession number(s) can be found in the article/supplementary material.

\section{REFERENCES}

Arulazhagan, P., and Vasudevan, N. (2011). Biodegradation of polycyclic aromatic hydrocarbons by a halotolerant bacterial strain Ochrobactrum sp. VA1. Mar. Pollut. Bull. 62, 388-394. doi: 10.1016/j.marpolbul.2010.09.020

Azubuike, C. C., Chikere, C. B., and Okpokwasili, G. C. (2016). Bioremediation techniques-classification based on site of application: principles, advantages, limitations and prospects. World J. Microbiol. Biotechnol. 32:180. doi: 10.1007/s11274-016-2137-x

Bai, J., Wen, J. P., Li, H. M., and Jiang, Y. (2007). Kinetic modeling of growth and biodegradation of phenol and $\mathrm{m}$-cresol using Alcaligenes faecalis. Process Biochem. 42, 510-517. doi: 10.1016/j.procbio.2006.10.004

Bouabidi, Z. B., El-Naas, M. H., and Zhang, Z. (2019). Immobilization of microbial cells for the biotreatment of wastewater: a review. Environ. Chem. Lett. 17, 241-257. doi: 10.1007/s10311-018-0795-7

Disi, Z., Al, J. S., Al-Thani, D., Al-Meer, S., and Zouari, N. (2017). Considering the specific impact of harsh conditions and oil weathering on diversity, adaptation, and activity of hydrocarbon-degrading bacteria in strategies of bioremediation of harsh oily-polluted soils. Biomed Res. Int. 2017:8649350. doi: $10.1155 / 2017 / 8649350$

Elazzazy, A. M., Abdelmoneim, T. S., and Almaghrabi, O. A. (2015). Isolation and characterization of biosurfactant production under extreme environmental conditions by alkali-halo-thermophilic bacteria from Saudi Arabia. Saudi J. Biol. Sci. 22, 466-475. doi: 10.1016/j.sjbs.2014.11.018

Elbeshbishy, E. (2014). "Metabolic pathways | release of energy (Anaerobic)," in Encyclopedia of Food Microbiology, 2nd Edn, eds C. E. Batt and M.-L. Tortorello (London: Elsevier), 588-601.

El-Naas, M. H., Mourad, A. H. I., and Surkatti, R. (2013). Evaluation of the characteristics of polyvinyl alcohol (PVA) as matrices for the immobilization of Pseudomonas putida. Int. Biodeterior. Biodegrad. 85, 413-420. doi: 10.1016/j.ibiod.2013.09.006

El-Naas, M. H., Surkatti, R., and Al-Zuhair, S. (2016). Petroleum refinery wastewater treatment: a pilot scale study. J. Water Process Eng. 14, 71-76. doi: 10.1016/j.jwpe.2016.10.005

El-Sayed, W. S., Ibrahim, M. K., Abu-Shady, M., El-Beih, F., Ohmura, N., Saiki, H., et al. (2003). Isolation and identification of a novel strain of the genus Ochrobactrum with phenol-degrading activity. J. Biosci. Bioeng. 96, 310-312. doi: $10.1263 / \mathrm{jbb} .96 .310$

Enyi, G., Nasr, G., and Burby, M. (2013). Economics of wastewater treatment in GTL plant using spray technique. Int. J. Energy Environ. 2, 571-582. Available online at: https://www.IJEE.IEEFoundation.org

Essam, T., Amin, M. A., Tayeb, O., El, M., B., and Guieysse, B. (2010). Kinetics and metabolic versatility of highly tolerant phenol degrading Alcaligenes strain TW1. J. Hazard. Mater. 173, 783-788. doi: 10.1016/j.jhazmat.2009.09.006

Fritsche, W., and Hofrichter, M. (2008). "Aerobic degradation by microorganisms," in Biotechnology Environmental Processes II, 2nd Edn. Vol. 11b, eds H.-J. Rehm and G. Reed (Weinheim: Wiley-VCH Verlag GmbH), 144-164.

Gunasundari, D., and Muthukumar, K. (2013). Simultaneous Cr(VI) reduction and phenol degradation using Stenotrophomonas sp. isolated from tannery

\section{AUTHOR CONTRIBUTIONS}

RS, ME-N, and ZA conceived the original idea and designed the experimental program. RS and ZA carried out the experiments and prepared the initial draft. $\mathrm{ME}-\mathrm{N}$ and $\mathrm{NZ}$ revised the manuscript with support from ZA and RS. MV and UO helped with discussion of the results and manuscript revisions.

\section{ACKNOWLEDGMENTS}

The authors would like to acknowledge the support of Qatar National Research Fund (a member of Qatar Foundation) through Grant \# NPRP 100129170278. The findings achieved herein are solely the responsibility of the authors.

effluent contaminated soil. Environ. Sci. Pollut. Res. 20, 6563-6573. doi: 10.1007/s11356-013-1718-6

Jia, X., Wen, J., Jiang, Y., Bai, J., and Chen, X. (2005). Modeling for batch phenol biodegradation with immobilized Alcaligenes faecalis. AIChE J. 52, 1294-1303. doi: 10.1002/aic

Jiang, Y., Wen, J., Bai, J., Jia, X., and Hu, Z. (2007). Biodegradation of phenol at high initial concentration by Alcaligenes faecalis. J. Hazard. Mater. 147, 672-676. doi: 10.1016/j.jhazmat.2007.05.031

Kumar, B. L., and Gopal, D. V. R. S. (2015). Effective role of indigenous microorganisms for sustainable environment. 3 Biotech 5, 867-876. doi: 10.1007/s13205-015-0293-6

Kumar, S., Stecher, G., Li, M., Knyaz, C., and Tamura, K. (2018). MEGA X: Molecular evolutionary genetics analysis across computing platforms. Mol. Biol. Evol. 35, 1547-1549. doi: 10.1093/molbev/msy096

Lane, D. (1991). "16S/23S rRNA sequencing," in Nucleic Acid Techniques in Bacterial Systematics, eds E. Stackebrandt, and M. Goodfellow (New York, NY: John Wiley and Sons), 115-175.

Majone, M., Aulenta, F., Dionisi, D., D’Addario, E. N., Sbardellati, R., Bolzonella, D., et al. (2010). High-rate anaerobic treatment of fischer-tropsch wastewater in a packed-bed biofilm reactor. Water Res. 44, 2745-2752. doi: 10.1016/j.watres.2010.02.008

Neerackal, G. M., Ndegwa, P. M., Joo, H. S., Wang, X., Frear, C. S., Harrison, J. H., et al. (2016). Potential application of Alcaligenes faecalis strain No. 4 in mitigating ammonia emissions from dairy wastewater. Bioresour. Technol. 206, 36-42. doi: 10.1016/j.biortech.2016.01.063

Neoh, C. H., Lam, C. Y., Ghani, S. M., Ware, I., Hajar, S., Sarip, M., et al. (2016). Bioremediation of high-strength agricultural wastewater using Ochrobactrum sp. strain SZ1. 3 Biotech. 6:143. doi: 10.1007/s13205-016-0455-1

Patel, K., and Patel, M. (2020). Improving bioremediation process of petroleum wastewater using biosurfactants producing Stenotrophomonas sp. S1VKR26 and assessment of phytotoxicity. Bioresour. Technol. 315:123861. doi: 10.1016/j.biortech.2020.123861

Qiu, X., Zhong, Q., Li, M., Bai, W., and Li, B. (2007). Biodegradation of p-nitrophenol by methyl parathion-degrading Ochrobactrum sp. B2. Int. Biodeterior. Biodegrad. 59, 297-301. doi: 10.1016/j.ibiod.2006.09.005

Saitou, N., and Nei, M. (1987). The neighbor-joining method: a new method for reconstructing phylogenetic trees. Mol. Biol. Evol. 4, 406-425. doi: 10.1093/oxfordjournals.molbev.a040454

Senthilvelan, T., Kanagaraj, J., Panda, R. C., and Mandal, A. B. (2014). Biodegradation of phenol by mixed microbial culture: an eco-friendly approach for the pollution reduction. Clean Technol. Environ. Policy 16, 113-126. doi: 10.1007/s10098-013-0598-2

Shokrollahzadeh, S., Azizmohseni, F., Golmohammad, F., Shokouhi, H., and Khademhaghighat, F. (2008). Biodegradation potential and bacterial diversity of a petrochemical wastewater treatment plant in Iran. Bioresour. Technol. 99, 6127-6133. doi: 10.1016/j.biortech.2007.12.034

Stecher, G., Tamura, K., and Kumar, S. (2020). Molecular evolutionary genetics analysis (MEGA) for macOS. Mol. Biol. Evol. 37, 1237-1239. doi: $10.1093 / \mathrm{molbev} / \mathrm{msz} 312$ 
Subashchandrabose, S. R., Megharaj, M., Venkateswarlu, K., Lockington, R., and Naidu, R. (2013). Influence of nutrient mixtures on p-nitrophenol degradation by Stenotrophomonas sp. isolated from groundwater. J. Environ. Sci. Heal. A Toxic Hazardous Subst. Environ. Eng. 48, 108-119. doi: 10.1080/10934529.2012.707861

Surkatti, R., El-Naas, M. H., Loosdrecht, M. C. M., van Benamor, A., Udeogu, O., and Al-Naemi, F. (2020). Biotechnology for Gas-to-Liquid (GTL)wastewater treatment: a review. Water 12:2126. doi: 10.3390/w120 82126

Survery, S., Ahmad, S., Abu Subhan, S., Ajaz, M., and Rasool, S. A. (2005). Hydrocarbon degrading bacteria from Pakistani soil: isolation, identification, screening and genetical studies. Pakistani J. Biol. Sci. 7, 1518-1522. doi: $10.3923 /$ pjbs.2004.1518.1522

Tamura, K., Nei, M., and Kumar, S. (2004). Prospects for inferring very large phylogenies by using the neighbor-joining method. Proc. Natl. Acad. Sci. U.S.A. 101, 11030-11035. doi: 10.1073/pnas.04042 06101

Wang, D., Ma, W., Han, H., Li, K., Xu, H., Fang, F., et al. (2016). Enhanced anaerobic degradation of fischer-tropsch wastewater by integrated UASB system with Fe-C micro-electrolysis assisted. Chemosphere 164, 14-24 doi: 10.1016/j.chemosphere.2016.08.074

Zacharia, R., El-Naas, M. H., and Al-Marri, M. J. (2018). "Chapter 15: photocatalytic oxidation of non-acid oxygenated hydrocarbons: application in GTL process," in Water Management: Social and Technological Perspectives, eds M. K. AMOSA, I. M. Mujtaba, and T. Majozi (Taylor \& Francis Ltd.) doi: $10.1201 / \mathrm{b} 22241-15$

Conflict of Interest: The authors declare that the research was conducted in the absence of any commercial or financial relationships that could be construed as a potential conflict of interest.

Copyright (C) 2021 Surkatti, Al Disi, El-Naas, Zouari, Van Loosdrecht and Onwusogh. This is an open-access article distributed under the terms of the Creative Commons Attribution License (CC BY). The use, distribution or reproduction in other forums is permitted, provided the original author(s) and the copyright owner(s) are credited and that the original publication in this journal is cited, in accordance with accepted academic practice. No use, distribution or reproduction is permitted which does not comply with these terms. 